\title{
Investigating the learning challenges presented by digital technologies to the College of Education in Kuwait University
}

\author{
Fayiz Aldhafeeri ${ }^{1}$ - Trevor Male ${ }^{2}$
}

(C) Springer Science+Business Media New York 2015

\begin{abstract}
There is now widespread recognition that digital technologies, particularly portable hand held devices capable of Internet connection, present opportunities and challenges to the way in which student learning is organized in schools, colleges and institutions of higher education in the 21st Century. Traxler, Journal of the Research Centre for Educational Technology, 6(1), 3-15 (2010) suggests such devices are pervasive and ubiquitous, conspicuous and unobtrusive, noteworthy and taken-forgranted with everyone typically owning one, using one and often having more than one. As a consequence it has been argued that the availability of such devices, controlled mainly by the student and not the teacher, has the potential to change the traditional dynamics and pedagogical patterns of the learning environment (Burden et al. 2012). Education institutions, however, typically remain organized around spatial and temporal considerations such as buildings, timetables, calendars and internal structures which are designed to classify and manage students. In the case study reported here students and faculty teaching staff from the College of Education in the Kuwait University were surveyed in order to assess their access to such technologies, their capability to use them effectively in support of achieving planned learning outcomes and the implications for change that could emanate from such findings.
\end{abstract}

Keywords University · Technology · Education · Teaching · Learning

\section{Introduction}

This paper investigates the extent to which a faculty within Kuwait University is prepared to deal with the potential impact of digital technologies on learning. The

Trevor Male

t.male@ioe.ac.uk

1 Kuwait University, Kuwait City, Kuwait

2 UCL Institute of Education, London, UK 
investigation was initially undertaken via a questionnaire survey of academic staff and students from the College of Education conducted in May 2013, with a follow up focus group meeting in February, 2014 held with undergraduate and postgraduate students in an attempt to verify some of the questionnaire findings.

There is very little difference between Kuwait University and other universities in the region or, in many ways, from institutions of higher education across the world. Most student learning is organized around face to face taught sessions with an expectation that students will undertake further study as appropriate in non-contact times. In keeping with other universities in the Gulf States the major concern in terms of higher education provision is one of supply in that generally there is greater demand than capacity for student numbers. The university is not dependent on per capita student income and is thus not in a market driven economy. In addition being a small country geographically means that students can access the campus buildings and facilities relatively easily which consequently reduces the necessity for the university to provide distance learning. The organization of student learning has tended to follow traditional models, therefore, with academic staff presenting knowledge for student consumption via lectures, seminars and directed reading. Whilst there is widespread use of computer technology in the university in terms of support for learning this equipment seems only to be used for presentation of material during taught sessions or as a repository for materials through use of a virtual learning environment (VLE).

Most members of the university have ready access to digital technologies, however, particularly portable hand held devices capable of Internet connection. Such technologies present opportunities and challenges to the way in which student learning is organized in the 21st Century. Traxler (2010) suggests such devices are pervasive and ubiquitous, with the availability of such devices, controlled mainly by the student and not the teacher, having the potential to change the traditional dynamics and pedagogical patterns of the learning environment (Burden et al. 2012).

In the case study reported here students and faculty teaching staff from the College of Education were surveyed in order to assess their access to such technologies, their capability to use them effectively in support of achieving planned learning outcomes and the implications for change that could emanate from such findings. Whilst the use of digital technologies is of importance to all faculties within the university there are particular (and additional) expectations of graduates from the College of Education to lead learning for the next generation and to ensure full engagement with a world economy that will be underpinned by technological advances. Consequently whilst the outcomes from this investigation will be of relevance to most aspects of learning provision in universities, they will be of special interest to faculties developing future educators.

\section{Digital technologies and learning}

The term 'digital technologies' in this study refers primarily to multi-functional equipment or devices with Internet connectivity and particularly to devices that are handheld and portable, a definition which generally means smart-phones and tablet computers. In exploring the opportunities offered through the combination of more traditional Internet access (fixed location) and personal Internet access (mobile) a number of trends have been identified which universities need to explore, evaluate and possibly adopt as they 
move forward in a new era. The range of possibilities generally relate to two principal areas of provision: enhancing student learning through use of appropriate technologies and software applications or changing the nature of provision to recognize alternative pathways for student achievement and new markets. Given the nature of university provision in Kuwait, whereby expectations are traditional and government support for student participation is full, the second range of possibilities was not considered. Based on that decision, therefore, this article seeks to explore the range of possibilities available to academic staff in the university to enhance the learning experience for students on their programmes of study. Such opportunities extend beyond more effective use of readily available software, and in particular presentations based on PowerPoint or Prezi, and include networking and collaborative learning.

Portable digital devices are now a core feature of the 21 st Century and present the possibility for a fundamental change to education, shifting from passive acquisition of someone else's ideas to active learning experiences that empower people to inquire, critique, create, collaborate, problem solve, and create understanding (Dede and Barb 2009). With new technologies information is continually being developed, distributed and acquired and has become a paradigm that cannot be ignored within educational organizations (Courville 2011). Selwyn (2007: 91) makes the case that these digital technologies could allow universities to reinvent themselves, requiring institutions to make a shift "from the representational capabilities of ICTs (i.e., their ability to represent commoditized informational delivery modes of higher education) to their more expansionist and relational potentials". In examining these changes the American Society for Training and Development (2009) not only reflected the way in which the 'millennials' (those born between 1977 and 1997) approach learning, but also identified the need to incorporate these digital technologies into the workforce of the future:

The online world has redesigned communication in and outside the workplace; anyone can access almost anything about a topic, so [young people] are now accustomed to accessing mutliple open sources of information for solutions. As a result there are more collaborative technologies that have enabled the learning process to evolve from a fixed series of discrete training events into an informal, ongoing experience. Learning can easily occur anytime, anywhere and in a variety of formats. ( $\mathrm{p} 3$ )

Such technologies offer the potential for different forms of learning and teaching where academic staff and students can change or transform their perspectives and meanings as a result of their interactions and use of digital technologies. The 'pushpull' architecture of the Internet invites participation, generating symmetry between production and consumption which is not evident in traditional 'broader-casting' mediums such as television or traditional models of formal learning. Tools such as wikis, social networking software (e.g., FaceBook) and aggregator services (sites which bring together artefacts from other places) are identified as the means by which educators might shift the emphasis of their teaching by empowering the student to see themselves as knowledge co-constructors rather than passive recipients of information provided. In an era when knowledge is no longer fixed and is subject to challenge on the very public platform of the Internet students need the skills to explore and synthesize data in order to determine knowledge and construct meaning. 
In this emerging digital age models of learning based on behaviourism and cognitive approaches are being overtaken in this by connectivism, an approach first offered by Siemens (2009). Connectivism defines learning as a continual process which occurs in different settings, including communities of practice, personal networks and work places and allows teachers to shift focus from their textbooks and presentation to the actual student. Knowledge is emphasized by this theory, which stresses the need to help students gather, access, synthesize and publish knowledge in print or in online media. This knowledge is no longer under the control of experts, but has been distributed and is accessible to average students. In connectivist-based learning, the role of the teacher has changed from that of providing material and presenting lectures to one of helping students create, publish and share knowledge using Internet-based technologies. Consequently connectivism suggests giving the learner the control to explore objectives defined by that learner (Giesbrecht 2007). In order to facilitate the interaction both synchronous and asynchronous tools are essential as extensions of course environments. With connectivisim, active participation is required by all involved in the learning process and matches the aspirations offered by Confucius: "Tell me, and I will forget; show me, and I will remember; involve me, and I will understand."

Based on the above discourse we devised a model which seeks to guide learning in university education beyond self-managed learning and, in this instance, an approach to student learning that makes full use of digital technologies (see Fig. 1, below). As Crook (2008) indicates, the learning process in university education requires greater self-management of learning as they progress from entry stage to graduation and on to postgraduate level and, in a digital age, engagement with other students in a collaborative mode. We argue that in addition student learning potential will be enhanced by use of digital technologies that are now readily available and foresee the ultimate aim of such education as being the creation of effective learning environments through interdependency, a state often seen as ideal in the world of work where problem solving and creativity are the product of collaboration rather than independent contributions as suggested earlier (Helfand 2013).

This investigation sought, therefore, to explore ways in which mobile digital technologies are owned and used by staff and students within the College of

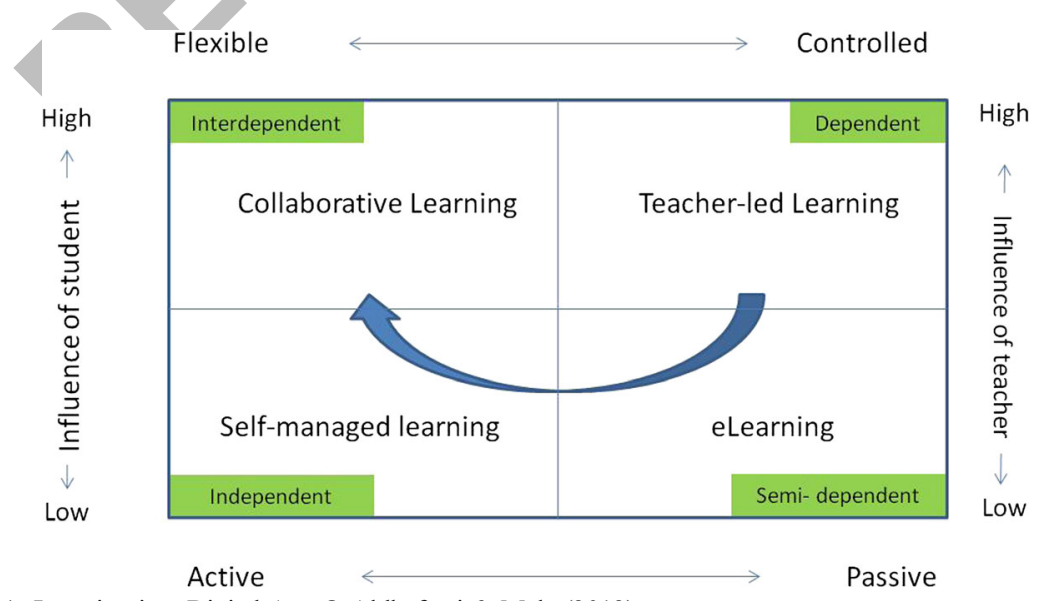

Fig. 1 Learning in a Digital Age (C) Aldhafeeri \& Male (2012) 
Education at the Kuwait University and, in particular, to determine the extent to which they are capable of using such technologies to support student learning.

\section{Methodology}

Data collection was though use of a bespoke questionnaire for students and academic staff in the College of Education. Work began on the questionnaire in 2012 and comprised questions regarding demographics and the perceived experience, capability and attitudes of respondents to use computers and mobile technologies in support of student learning on degree programmes within the college. The questionnaire design was based on a series of surveys undertaken in UK schools by Burden et al, (2012). These questions were adapted for context, translated into Arabic by the first author and constructed using SurveyMonkey. After piloting with academic staff and students from the university in early 2013 the final on-line questionnaire was administered to 43 members of academic teaching staff and 443 undergraduate and postgraduate students in May 2013.

The student population for this survey largely comprised Kuwaiti nationals (86\%) of whom most were female $(81 \%)$. Most student participants had studied in the College of Education longer than one full academic year (94\%; ' $n$ ' of 409), with $65 \%$ of the survey population either being in their fourth year of study (' $n$ ' 198) or for having studied longer (' $n$ ' 83). It is reasonable to assume, therefore, that the majority of the student participants are familiar with the teaching styles and behaviours of most academic staff in the College. 43 members of academic staff participated in the questionnaire survey of which $93 \%$ ('n'38) of those who gave their nationality were Kuwaiti. The gender split of academic staff was virtually equal, with the majority (68\%) between 35 and 65 years of age. The total population of academic staff consisted of nine teaching assistants, 16 instructors, nine assistant professors and two professors. Most (63\%; 'n' 27) had been in post at the university more than 10 years with just $19 \%$ ('n' 8) being within the first 3 years of service. Given the relatively small number of the academic population statistical analysis of the variables (e.g., age, length of service) was considered not to be viable, with the consequence that the findings for this group are not differentiated. Given the shortest period of service by any member of academic staff was at least 1 year it is reasonable to assume, in the same way as the student population, that the majority were familiar with the range of computer technologies available within the university.

The outcomes of the initial survey produced an interesting finding, however, in that academic staff not only indicated a higher level of ownership of personal mobile digital devices than the student body, but also perceived themselves to be at least as capable as students in the use of such equipment to support teaching and learning in the college. This finding was not as expected in that the survey results appeared to show no evidence of a digital divide (for example, such as the idea of digital 'natives' and 'immigrants' offered by Prensky 2001) between staff and students in current provision as was anticipated both from hypotheses and personal observations by both researchers. Consequently a second stage of research was instigated in terms of a group interview, led by the second author, that was held in spoken English with 10 students in February 2014. The group was evenly split in numbers between undergraduates and 
postgraduates from the College of Education. Of the five undergraduates three were in their second year and the other two in their third year. The interview was audio recorded and subsequently analyzed through repeated playback to establish core themes and issues. Participants were advised that their names and/or identities would not be revealed at any stage of the subsequent analysis and reporting and were provided with a copy of the conclusions drawn for verification purposes. Seven of the original interview group responded to this invitation and indicated full agreement with the conclusions.

\section{Findings}

\subsection{Personal ownership of devices}

As can be seen in Table 1 there was almost universal ownership of at least one portable digital device with Internet access by all members of academic staff and students. A mobile phone with Internet access was the most common device although ownership was divided between iPhone, Androids and Smartphones (Blackberry) each of which had different operating systems and, thereby, different applications software (apps). At the time of the initial survey there were no Windows phones. Tablet devices were more common amongst academic staff than with students with iPad being dominant. There were relatively low levels of personal ownership of other devices such as (separate) music and games players, presumably as most tablets and phones have such operations included as standard items.

\subsection{Personal use of devices}

Table 2 demonstrates academic staff claiming greater regularity of use of their digital devices in support of university work at home (off campus) than the student body. Here

Table 1 Percentage of personal ownership of digital devices

\begin{tabular}{lll}
\hline & Academic staff & Students \\
\hline iPad & 63 & 27 \\
Other tablet device & 8 & 5 \\
iPhone & 75 & 55 \\
Blackberry & 8 & 35 \\
Android phone & 25 & 24 \\
Different mobile phone with Internet & 23 & 11 \\
A mobile phone without Internet & 15 & 4 \\
Music player & 13 & 9 \\
Games player & 8 & 9 \\
Digital still camera & 28 & 16 \\
Digital video camera & 20 & 7 \\
I don't own any of these & 0 & $>1$ \\
\hline
\end{tabular}


Table 2 Percentage use of digital devices at home in support of university work

\begin{tabular}{|c|c|c|c|c|c|c|}
\hline \multirow[t]{2}{*}{ Personal device } & \multicolumn{2}{|c|}{ Daily use } & \multicolumn{2}{|c|}{ Weekly } & \multicolumn{2}{|c|}{ Sometimes/Never } \\
\hline & Staff & Students & Staff & Students & Staff & Students \\
\hline Laptop computer/netbook & 62 & 29 & 26 & 42 & 13 & 28 \\
\hline iPad or digital tablet & 47 & 35 & 9 & 42 & 44 & 23 \\
\hline Mobile phone - Internet access & 97 & 78 & 0 & 18 & 3 & 4 \\
\hline Other mobile phone & 33 & 10 & 0 & 17 & 83 & 73 \\
\hline Music player & 4 & 42 & 4 & 22 & 92 & 69 \\
\hline Digital still camera & 13 & 17 & 10 & 31 & 77 & 56 \\
\hline Digital video camera & 4 & 11 & 4 & 35 & 93 & 49 \\
\hline
\end{tabular}

again the mobile phone with Internet access was the most common device with virtually all academic staff (97\%) claiming daily use. Similarly the majority (56\%) of academic staff claimed greater daily use of laptop computers and tablets, although the figures are more balanced with students when considering weekly use. Other equipment was used far less frequently by all participants in the survey.

\subsection{Frequency of activities}

Academic staff once again claimed more regular use of their devices and software applications than students, including sending and receiving emails, texts and instant messages (Table 3). There was a balance between the groups in terms of research on the Internet for university work, but a clear indication that students made greater use of social networking with $54 \%$ of academic staff indicating that they only used such sites episodically, if ever. In addition there were low levels of use by academic staff on with downloading or uploading music and video, although these were also activities that were less popular with students.

Table 3 Percentage frequency of undertaking activities on digital devices

\begin{tabular}{|c|c|c|c|c|c|c|}
\hline \multirow[t]{2}{*}{ Frequency of activities } & \multicolumn{2}{|c|}{ Daily use } & \multicolumn{2}{|c|}{ Weekly } & \multicolumn{2}{|c|}{ Sometimes/Never } \\
\hline & Staff & Students & Staff & Students & Staff & Students \\
\hline Send or read email & 73 & 17 & 15 & 17 & 13 & 66 \\
\hline Send or receive texts & 87 & 55 & 8 & 19 & 5 & 26 \\
\hline Send or receive instant messages & 98 & 91 & 0 & 4 & 3 & 5 \\
\hline Research on Internet for work & 41 & 43 & 31 & 33 & 28 & 24 \\
\hline Use chat forums & 19 & 16 & 3 & 12 & 78 & 72 \\
\hline Social networking & 24 & 55 & 22 & 17 & 54 & 29 \\
\hline Download video or music & 17 & 30 & 11 & 26 & 72 & 45 \\
\hline Upload images or video & 8 & 23 & 8 & 19 & 84 & 58 \\
\hline
\end{tabular}




\subsection{Perceived competency}

Table 4 demonstrates that students considered themselves marginally more competent in the range of devices, software and applications listed below. Both groups considered themselves as competent in most aspects of use at similar levels, however, except with editing and production of images and audio outputs where students perceived themselves as more capable users.

\subsection{Academic staff supporting learning}

Table 5 demonstrates a clear divide in perceived capability, however, with students indicating irregular use of software applications by academic staff in support of learning. There is disparity in response to the only common question - the use of presentation software such as PowerPoint or Prezi-where $87 \%$ of academic staff indicating they used it always or regularly whereas $40 \%$ of students suggested the regularity of such use was only sometimes or never. Students indicated similar irregular use of other applications in terms of support for learning with a range of 54 to $80 \%$ indicating academic staff only using such applications sometimes or never.

\subsection{Student focus group}

Such was the divide between the two groups in regard to the perceptions of capability that further research was undertaken through the establishment of a student focus group (see above). Here student participants generally expressed doubt on the claims made by

Table 4 Perceived Competency in use of technologies

\begin{tabular}{|c|c|c|c|c|c|c|c|c|}
\hline \multirow{3}{*}{$\begin{array}{l}\text { Competency in using these technologies } \\
\text { Answer options }\end{array}$} & \multicolumn{4}{|c|}{ Some skills } & \multicolumn{4}{|c|}{ Highly competent } \\
\hline & \multicolumn{2}{|c|}{ Academic staff } & \multicolumn{2}{|l|}{ Students } & \multicolumn{2}{|c|}{ Academic staff } & \multicolumn{2}{|l|}{ Students } \\
\hline & 'N' (40) & $\%$ & ${ }^{N}{ }^{\prime}(336)^{a}$ & 5 & 'N' (40) & $\%$ & 'N' (336) & $\%$ \\
\hline A computer (desktop) & 35 & 88 & 321 & 96 & 17 & 43 & 165 & 51 \\
\hline Laptop computer or notebook & 35 & 90 & 292 & 87 & 16 & 41 & 156 & 53 \\
\hline iPodtouch or iPad & 25 & 68 & 307 & 92 & 8 & 22 & 206 & 67 \\
\hline Word Processing & 33 & 85 & 294 & 89 & 23 & 59 & 195 & 66 \\
\hline Spreadsheets & 30 & 77 & 238 & 71 & 14 & 36 & 91 & 38 \\
\hline Graphics & 21 & 57 & 208 & 63 & 9 & 24 & 78 & 38 \\
\hline Presentation software & 28 & 76 & 293 & 88 & 20 & 54 & 201 & 69 \\
\hline Email & 33 & 94 & 293 & 89 & 24 & 69 & 220 & 75 \\
\hline Internet for search & 37 & 95 & 322 & 97 & 33 & 85 & 284 & 88 \\
\hline Digital image editing & 18 & 53 & 245 & 74 & 3 & 9 & 118 & 48 \\
\hline Digital video editing & 16 & 46 & 187 & 56 & 4 & 11 & 67 & 36 \\
\hline Music production and editing & 6 & 16 & 135 & 41 & 0 & 0 & 46 & 34 \\
\hline Making podcasts & 10 & 26 & 146 & 44 & 5 & 13 & 47 & 32 \\
\hline
\end{tabular}

a Indicates total population, where ' $\mathrm{n}$ ' is actual number of responses 
Table 5 Percentage of academic staff use of digital devices and software to support learning

\begin{tabular}{|c|c|c|c|c|c|c|}
\hline \multirow[b]{2}{*}{ Academic staff use to support learning } & \multicolumn{2}{|c|}{ Always } & \multicolumn{2}{|c|}{ Regularly } & \multicolumn{2}{|c|}{ Sometimes/Never } \\
\hline & Staff & Students & Staff & Students & Staff & Students \\
\hline Email correspondence & $\mathrm{n} / \mathrm{a}$ & 10 & $\mathrm{n} / \mathrm{a}$ & 17 & $\mathrm{n} / \mathrm{a}$ & 74 \\
\hline Presentation Software & 57 & 25 & 30 & 35 & 13 & 40 \\
\hline Embed audio materials & - & 8 & - & 22 & - & 71 \\
\hline Embed video materials & - & 8 & - & 24 & - & 68 \\
\hline Have interactive presentations & - & 13 & - & 33 & - & 54 \\
\hline Use collaborative tools & - & 6 & - & 14 & - & 80 \\
\hline Use conference tools & - & 8 & - & 15 & & 76 \\
\hline Add open access support materials & - & 9 & - & 20 & & 72 \\
\hline
\end{tabular}

academic staff of competency and regularity of use of computer technologies in support of learning. One undergraduate student summed up these feelings with her statement that "really only a few [members of academic staff] use such technologies, not many of them at all". Where hardware was used by students it tended to be Android (typically for Internet access) and, for online work, a laptop computer. A typical taught session, suggested undergraduate students, consisted of lecturing and discussion without use of technology. Where any technology was used by academic staff the students indicated it was for demonstration of figures or documents rather than presentation. Postgraduate (taught) students reported more use of PowerPoint, virtual learning environments (VLE) and Internet resources (such as YouTube) by their teachers to initiate discussion, but only by five members of academic staff adding, "If he is young he uses the technology, if he is old he does not". Older staff, suggested the postgraduate students, tend to use books or pamphlets and sometimes without discussion. When confronted with the claim that $57 \%$ of academic staff always use presentation software in their lectures (see Table 4, above) the immediate response was "no they don't"!

The conclusion from this student focus group was that whilst some academic staff may be skilled and competent in the use of technology it was still not used extensively in face to face learning, a situation exacerbated by the classrooms which are not always fitted with appropriate equipment. Although a typical teaching room would have a projector and a Smartboard, little use was made of the latter and there were very few examples of live Internet use. Mobile phone use was not allowed during lectures, however, even for Internet searches for relevant materials. There was some evidence of the use of EdModo, an education specific online forum, for assignment writing and internal communication, but no examples of interactivity during taught sessions.

Conversely the students did report reasonably extensive use of online resources and VLEs for assignment writing, homework and examinations, although undergraduates were typically discouraged from using the Internet for research which was portrayed as problematic and unreliable as a data source. Postgraduates reported, however, they were expected to research the Internet, but to be discerning in their presentation of findings and to present syntheses of their enquiries. There was an assertion, particularly by postgraduate students, that use of mobile phones with Internet tended to be for social rather than academic reasons both by academic staff and students. Interestingly, 
however, all participants in the focus group indicated they used their mobile phone as the primary point of access to the Internet in preference to laptop computer or digital tablets which were used more for document production.

\section{Discussion \& conclusions}

It can be seen from the results of the questionnaire survey that academic staff and students are well equipped with personal mobile digital devices and generally consider themselves to be competent users of such equipment and associated software applications. Nevertheless there was little evidence to suggest use of digital technologies to enhance student learning other than a claim by academic staff that they employ presentation software extensively in their teaching (a claim challenged by students). The use of portable digital devices, particularly mobile phones, appeared to be actively discouraged in taught sessions. Social media, it appears, is used precisely for the purpose of socializing and not to support student learning. Finally, although there was the suggestion of the use of hybrid learning this was seen to be mainly the use of VLE as a repository for teaching materials with no evidence of interactive tasking.

The conclusion to be drawn is that there is ineffective use of available digital technologies which is probably more to do with attitude rather than lack of opportunities and skills. The only two lines of defence offered by students for academic staff not engaging more fully with digital technologies to support learning were that the amount of lecture time available militated against the complexity of using multiple platforms for investigating knowledge and, secondly, that too few teaching spaces had permanent Internet access. Whilst these are valid reasons in terms of fixed or portable computer equipment these are not excuses for failing to take advantage of the capability to utilise the potential of personal mobile devices with Internet access. Whist it is clear that the university and its academic staff have recognised and realised the potential of online learning, most obviously through the use of VLEs, there was too little substantive evidence of digital technologies being used adequately or effectively in the taught learning environment.

This research within the College of Education at the Kuwait University appears to mirror, therefore, the current situation that seemingly permeates all phases of education globally in that the technology exists, as does the capability to use it, but the willingness to exploit personal mobile digital devices and associated software applications is limited. The source of such limitation is typically based around intransigence of teaching staff to adapt their practice, a response often disguised through concerns about student safety and the validity of data sources when using the Internet (see, for example, Male and Burden 2013).

As discussed above, however, the potential use of digital technologies in university education is evolving rapidly and in the light, for example, of globalisation and employability this introduces an imperative for review and change of personal practice and organisational structures to accommodate new possibilities. Universities in the $21 \mathrm{st}$ Century will need to adapt their strategy and policy in regard to student learning to accommodate greater use of personal mobile digital technologies not only because they exist, but also in recognition of the opportunities to provide deeper, collaborative learning amongst students in the quest to further knowledge. Kuwait University, in 
keeping with most universities worldwide, should not be immune from such influences, but will need to take suitable action in the near future if it is to fulfil its ambition to provide its student body with the knowledge and skills to operate successfully in the international arena.

The findings from this specific enquiry have another vital factor for the College of Education also to consider in that most, if not all, of their students are being developed to work in the national education system. The majority of graduates from the college are likely to be in direct contact with the next generation either as teachers in schools or educators in other aspects of provision and face the task of changing the face of education to reflect the way in which technology can influence and enhance learning. Technology, states the national report on the development of education in Kuwait, "has become a reality we must deal with [...] to be producers of knowledge and not just consumers alone" (Ministry of Education 2008: 24). A subsequent report on education commissioned by the government and published in 2013 indicates, however, that the use of technology in teaching, learning and in management is not pervasive throughout the school system and is below expectations (NIE 2103: 1). The report concludes that "having the technological infrastructure and the software applications is one thing utilizing technology effectively to achieve the desired learning outcomes is quite another" (NIE 2013: 80). This appears to be the position within Kuwait University as a whole, but given the expectation of future educators the need to develop use of digital technologies more directly in the learning process should be of especial interest and relevance to the College of Education.

\section{References}

American Society for Training and Development. (2009). Transforming learning with Web 2.0 technologies. Virginia: ASTD Research

Male, T. and Burden, K. (2013). Access Denied? Twenty-first Century Technology in Schools. Technology, Pedagogy and Education. Published on-line First on 16 December, 2013 - ID:864697. doi:10.1080/ 1475939X.2013.864697

Burden, K., Hopkins, P., Male, T., Martin, S., \& Trala, C. (2012). iPad Scotland evaluation. Hull: University of Hull. Courville, K. (2011). Technology and its use in education: Present roles and future prospects. Online Submission: ERIC. Accessed March, 2012.

Crook, C. (2008). Web 2.0 technologies for learning: the current landscape-opportunities, challenges and tensions. London: BECTA Research Reports.

Dede, C., \& Barb, S. (2009). Emerging technologies for learning science: a time of rapid advances. Journal of Scientific Educational Technology, 18, 301-304.

Giesbrecht, N. (2007). Connectivism: Teaching and Learning. Available at: http://sites.wiki.ubc.ca/etec510/ Connectivism:_Teaching_and_Learning. Accessed July, 2012.

Helfand, D. (2013). Watering the Roots of Knowledge through Collaborative Learning. Chronicle of Higher Education. Available at: https:/chronicle.com/article/Watering-the-Roots-of/140135/. Accessed March, 2014.

Ministry of Education. (2008). The national report: development of education in the State of Kuwait 20042008. Kuwait City: Ministry of Education.

National Institute of Education (NIE). (2013). A diagnostic study of education in Kuwait. Singapore: NIE.

Prensky, M. (2001). Digital natives, digital immigrants. On the Horizon, 9(5), 1-6.

Selwyn, N. (2007). The use of computer technology in university teaching and learning: a critical perspective. Journal of Computer Assisted Learning, 23, 83-94.

Siemens, G. (2009). Connectivism: A Learning Theory for the Digital Age. Available at: http://www. elearnspace.org/Articles/connectivism.htm. Accessed July, 2012.

Traxler, J. (2010). Will student devices deliver innovation, inclusion and transformation? Journal of the Research Centre for Educational Technology, 6(1), 3-15. 